\title{
Corrigendum
}

\section{Re-theorising mobility and the formation of culture and language among the Corded Ware Culture in Europe-CORRIGENDUM}

Kristian Kristiansen, Morten E. Allentoft, Karin M. Frei, Rune Iversen, Niels N. Johannsen, Guus Kroonen, Łukasz Pospieszny, T. Douglas Price, Simon Rasmussen, Karl-Göran Sjögren, Martin Sikora \& Eske Willerslev

Published by Cambridge University Press, 4 April 2017.

In the article by Kristiansen et al. (2017), the funding information supplied was incorrect. The correct details are as follows:

Research for this paper was part of the project 'Travels, Transmissions and Transformations in the $3^{\text {rd }}$ and $2^{\text {nd }}$ Millennium BC in Northern Europe: the Rise of Bronze Age Societies' at the University of Gothenburg, led by Kristian Kristiansen and funded by the European Research Council (ERC Advanced Grant ERC-2010-AdG-proposal 269442 THE RISE). It also produced the genetic and isotopic research behind the following articles: Allentoft et al. 2015; Pospieszny et al. 2015; Rasmussen et al. 2015; Sjögren et al. 2016. The project EUROLITHIC led by Guus Kroonen has received funding from the European Research Council under the European Union's Horizon 2020 research and innovation programme (grant agreement 716732).

\section{Full citation}

Kristiansen, K. et al. 2017. Re-theorising mobility and the formation of culture and language among the Corded Ware Culture in Europe. Antiquity 91: 334-47. https://doi.org/10.15184/aqy.2017.17

(C) Antiquity Publications Ltd, 2020 